\title{
A platform of comprehensive budget management system
}

\author{
Sheng Ma \\ Huanggang Normal University, College of Mathematics and Physics, Hubei, 438000 \\ Email:masheng666@126.com
}

Keywords: budget platform, reimbursement management, Java software Myeclipse

\begin{abstract}
In this paper, a practical value of budget management system is analyzed and discussed. For the sake of overall management company, we build a comprehensive budget management system based on business, and with the office platform, contract management, reimbursement, other related effectively business integrated financial management and control system.
\end{abstract}

\section{Introduction}

Comprehensive budget management is a set of all-around, full process and full participation management system that takes the company's internal budget management as the main line. The system proceed from the integral strategic target of the company, through the scientific budget process and reasonable organization guarantee system, balance the relationship between responsibilities, and fully coordinated all aspects of the company operations and management. It's a comprehensive closed loop control on the target setting, budget establishment, execution control, analysis and assessment for the company's operations, the implement of management activities on the basis of strategic decomposition and project planning. On the basis of the financial management business blueprint, most of the companies has gradually formed a relatively perfect comprehensive budget management system framework for many years of management practice and accumulation, and made the comprehensive budget management of group unified business specifications. At the same time, the comprehensive budget management in IT support system associated with the rules is still uneven in the construction of the provincial company and application level at present, and lack of effective support for the business specifications. In the backdrop of the financial centralization, promoting the standardization construction of the group's budget management and realizing the standardization and informatization of budget management become the inevitable requirements of the current situation.

The comprehensive budget management, a management system played a significant role in promoting modern enterprise maturity and development, is one main method of enterprise insides control system. Since the last century 20`s GE, DuPont, General Motors is generated in the United States, the method soon became the standard operating procedure of large industrial and commercial enterprises. From the initial plan, coordination, development to a comprehensive implementation of enterprise strategy management tool combined control, motivation, evaluation, and many other functions in 2013, comprehensive budget management increasingly play a key role in the enterprise internal control. As famous managerialist David Oliver says, comprehensive budget management is one 
of the few management control methods that can integrate enterprise all of the key problems in a system.

In the paper, using some softwares including Java software Myeclipse and SSM (Spring +Spring MVC + Mybaties) framework, this system utilizes the EXTJS, Mybaties, Runqian statements and DB2 database to complete the exploitation of the pages at the front desk and backstage function.

\section{Construction of the comprehensive budget system}

According to the analysis of system function, the function frame diagram of this system is shown below.

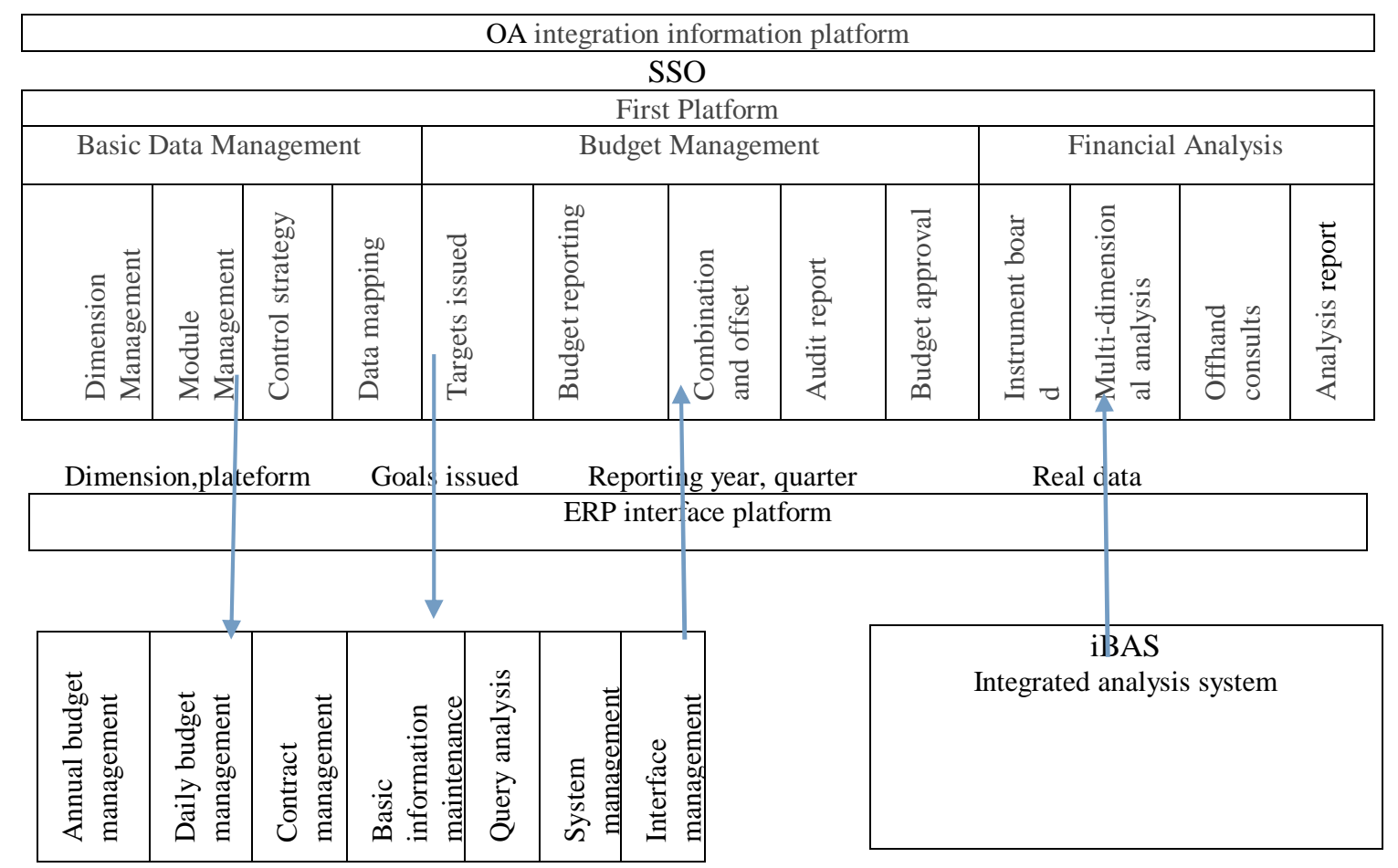

Basic building of the system is as follow.

(1) On the front page, the user can access through a web browser (Internet Explorer, for example) after that the system is deployed to Tomcat completely. Input the correct URL in the address bar and you will see the page. On the page, you need to enter the user name in the user name text box, enter the password in the password text box and click to log in to home page of the comprehensive budget management system level platform. When the administrator login successfully, click on the function menu on the left side of the page after entering the home page, then enter the page of system management. User management page is mainly divided into users searching and users list two plates. In it, users list plate lists each user's user name, real name, organization, coding and other detailed information, including new users, modify user, the configuration character, etc.

(2) Organization and Management: the page will be divided into three parts, respectively is: an organization tree on the left side, the detailed information on the upper right, and the sub-organization 
list on the lower right. The organization tree plate lists various subsidiaries subordinated to the company, click the "+" button in front of the company’s name to display subsidiaries and click the "-" button to hid subsidiaries. The detailed information plate shows code, name and other details of the selected organization, and the sub-organization list plate lists the sub-organizations of the selected organization.

(3) Subject Management: the function is divided into left and right two areas. There is a subject tree on the left, and subject editing area is on the right. You can select corresponding subjects or search course code through the subject tree on the left with course details displaying in the editing area on the right. If you choose subject editing area, sub disciplines will be listed below. In the editing area, you can add, modify, and delete the subjects.

(4) Scene Management: the function is divided into left and right two areas. There is a scene tree on the left, and subject editing area is on the right. You can select corresponding subjects, search scene code and scene name through the scene tree on the left with scene details displaying in the editing area on the right. If you choose scene editing area, sub scenes will be listed below. In the editing area, you can add, modify, and delete the scenes.

(5) Synthesis Management: the function is divided into left and right two areas. There is a synthesis tree on the left, and synthesis editing area is on the right. You can select corresponding subjects, search synthesis code and synthesis name through the synthesis tree on the left with synthesis information displaying in the editing area on the right. If you choose synthesis editing area, sub synthesis will be listed below. In the editing area, you can add, modify, and delete the synthesis.

(6) Trade Direction: the function is divided into left and right two areas. There is a trade direction tree on the left, and the trade direction editing area is on the right. You can select corresponding subjects, search trade direction code and trade direction name through the investment tree on the left with trade direction information displaying in the editing area on the right. If you choose trade direction editing area, sub trade direction subjects will be listed below. In the editing area, you can add, modify, and delete the trade direction.

(7) Version Management: the function is divided into left and right two areas. There is a version tree on the left, and the version editing area is on the right. You can select corresponding subjects, search version code and version name through the version tree on the left with version information displaying in the editing area on the right. If you choose version editing area, sub version subjects will be listed below. In the editing area, you can add, modify, and delete the version.

(8) Annual Budget Management: the management of the annual budget includes adding, deleting, and modifying. Annual information maintenance contains properties of the current year, to which only one year can be assigned. At the same time, the report of function and configuration items will show the corresponding information according to the current year data, and please carefully modify during the report. 


\section{The database design of the system}

The platform uses the star schema database design to ensure that the data's readability and flexibility.

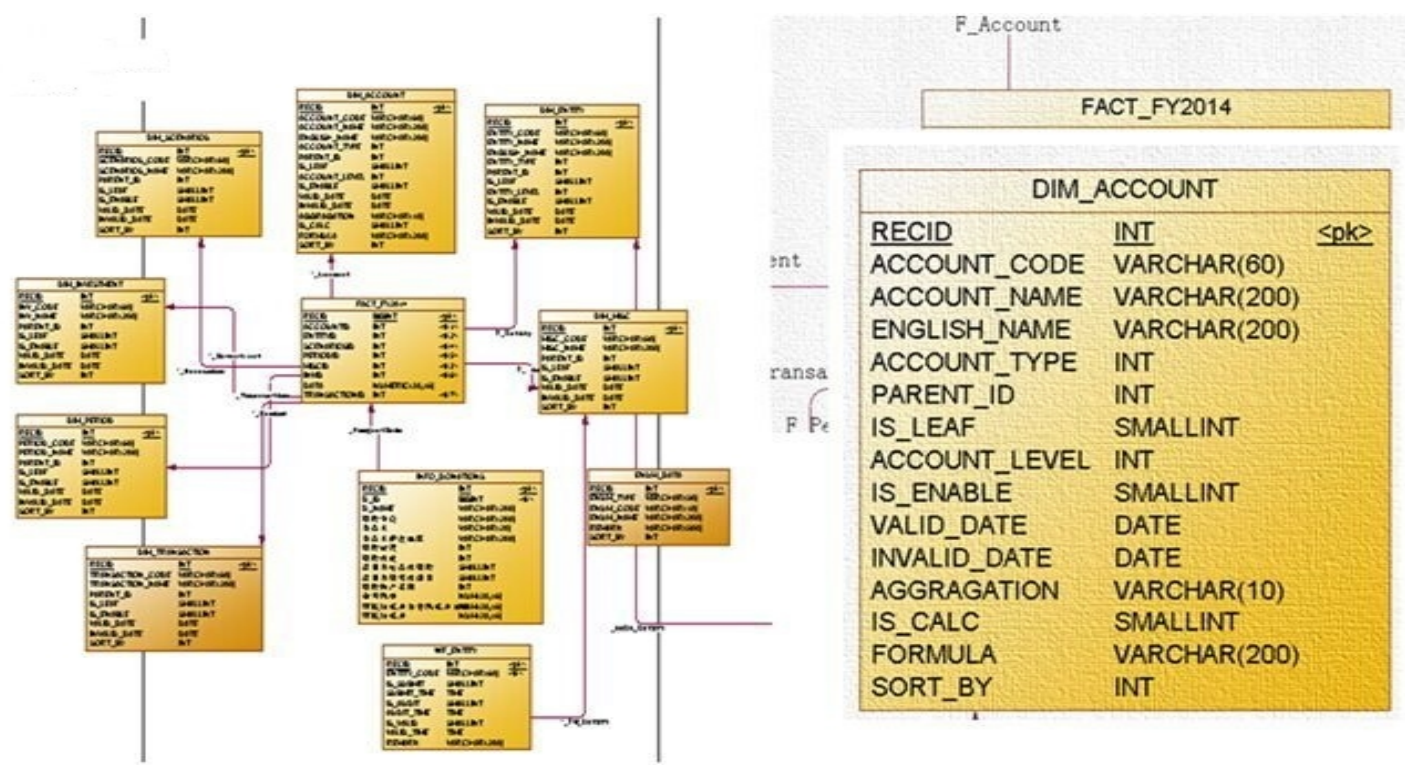

\section{System development platform}

Development of the system is under the environment of Tomcat. Tomcat is a free open source Servlet container. It is a core project of Apache foundation's Jakarta project, joint developed by Apache, Sun and some other companies and individuals. With the Sun's participation and support, the latest Servlet and Jsp specification can always reflected in the Tomcat. Tomcat is elected as the most innovative Java products by the Java World magazine's editors in 2001, which shows its position in the industry.

\section{Acknowledgements}

This work was financially supported by the Science Foundation of the university (2013ce22).

\section{References}

[1] Y.T.Ma. Eclipse Essentials and Advanced Development Technology. Electronic Industry Press, 2003.

[2] S.F.Luo. Proficient Spring- depth Java EE development of core technology. Electronic Industry Press, 2008.

[3]J.C.Zhao, H.T.Zhu, Y.R.Wu, ExtJS proficient JS script of the framework, the People's Posts and Telecommunications Press ,2011.

[4] Shea Frederick, Colin Ramsay, Steve Cutter Blades, Ext J study guide, the People's Posts and Telecommunications Press, 2009.

[5] Apache Software.The Struts User's Guide.http://Jakarta.Apache.org/struts. 